\title{
How Can ALSC Help You in Uncertain Times?
}

Cecilia McGowan, ALSC President

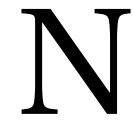

ow, more than ever, ALSC is here for you. Our memberdriven organization relies on your passion and commitment to children, families, and their caregivers. But you rely on us as well. These are hard times as we adjust to the impact of COVID-19. There is no sugarcoating how hard your lives are working from home if you're able to, managing if you're not. How can ALSC serve you through these dark times and sustain you when this crisis is over?

The health of our division depends on our connection to each other. What we have known for an exceptionally long time is that librarians that serve youth are some of the most inventive, flexible, accommodating, passionate, artful, talented, diverse, and collaborative. What makes us strong is our ability to reach out and share our ideas, our challenges, our solutions, and now, our fears and concerns about how we can best serve youth.

Because of the pressures impacting how ALA will hold meetings and conferences in the future, ALSC became proactive in looking at how we could best serve our members when we knew that in-person meetings during the winter event would be severely limited. What spurred this work, however, was a desire to fully engage more members in committee work. What could we do to increase participation when we knew that the majority of our members would have a difficult time attending two conferences a year? In November 2019, the ALSC Executive Committee began the exploration of how we could realign our committees into a hybrid model that would tap into the vast potential of our $4,000+$ members. In the process, we would become a more resilient, nimble, and streamlined. The ALSC Board of Directors approved the realignment during their February 20, 2020, online meeting. What does hybrid mean? The committee will engage in online meetings through the year with the hope that most committees will meet in person during the ALA Annual Conference (strongly encouraged, but not required). Book and media committees will continue to have face-to-face meetings, as currently required. We will transition to the new model with the new committee service year on July 1, 2020.
As we all know, Annual Conference has been cancelled due to COVID-19. This doesn't mean that our committees and board will not meet. We will-just not in person! Committees are asked to meet online to complete the work of their service year. Resources for virtual meetings are available on the ALSC website (www.ala.org/alsc) under Committee Resources. We are in the process of setting up our Board of Directors, Membership, and other governance meetings to take place over the next several months. The Membership committee is looking at developing ALSC 101 as an online networking event later this year, and as something to offer going forward to maximize engagement with members and potential members throughout the year. As the schedule firms up, it will be posted to the ALSC Conferences \& Events page (www.ala.org/alsc/ confevents). Please join us online for our meetings-we need your input! Additionally, staff are working to shift the planned educational content from Annual Conference into online courses and webinars. We are committed to offering quality professional development.

So now I'm turning to you. What are your ideas, your hopes, and your dreams, for making ALSC more inclusive, collaborative, and productive, particularly as we look to the future? Please reach out and let me know your thoughts, and we'll find a way to share them with other members.

Thank you for your membership, and your service to every person, not just youth, be it online or in person. Your work and service matters. And thank you for your support and encouragement. I'm honored to have been your president this year. \&

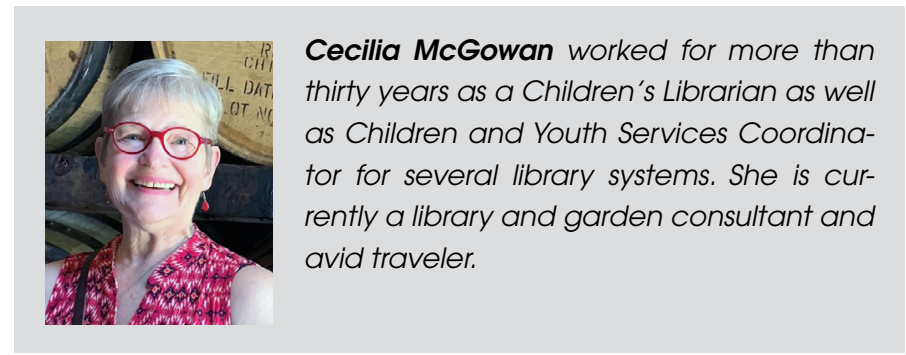

